Medicine, Division of Nephrology), J. Ormel (Department of Psychiatry, Interdisciplinary Center of Psychopathology of Emotion Regulation (ICPE)), D.S. Postma (Department of Pulmonology), J.G.M. Rosmalen (Department of Psychiatry, ICPE), J.P. Slaets (University Center for Geriatric Medicine), H. Snieder (Department of Epidemiology), R.P. Stolk (Department of Epidemiology), B.H.R. Wolffenbuttel (Department of Endocrinology) and C. Wijmenga (Department of Genetics), all at University of Groningen, University Medical Center Groningen, Groningen, The Netherlands.

\title{
References
}

1 World Health Organization. Burden of Disease from Ambient Air Pollution for 2012. www.who.int/phe/health_topics/ outdoorair/databases/AAP_BoD_results_March2014.pdf?ua=1 Date last accessed: November 12, 2015. Date last updated: March, 2014.

2 Adam M, Schikowski T, Carsin AE, et al. Adult lung function and long-term air pollution exposure. ESCAPE: a multicentre cohort study and meta-analysis. Eur Respir J 2015; 45: 38-50.

3 Forbes LJ, Kapetanakis V, Rudnicka AR, et al. Chronic exposure to outdoor air pollution and lung function in adults. Thorax 2009; 64: 657-663.

4 Ackermann-Liebrich U, Leuenberger P, Schwartz J, et al. Lung function and long term exposure to air pollutants in Switzerland. Study on Air Pollution and Lung Diseases in Adults (SAPALDIA) Team. Am J Respir Crit Care Med 1997; 155: 122-129.

5 Schikowski T, Sugiri D, Ranft U, et al. Long-term air pollution exposure and living close to busy roads are associated with COPD in women. Respir Res 2005; 6: 152.

6 Schikowski T, Mills IC, Anderson HR, et al. Ambient air pollution: a cause of COPD? Eur Respir J 2014; 43: 250-263.

7 Scholtens S, Smidt N, Swertz MA, et al. Cohort Profile: LifeLines, a three-generation cohort study and biobank. Int J Epidemiol 2015; 44: 1172-1180.

8 Gauderman WJ, Avol E, Gilliland F, et al. The effect of air pollution on lung development from 10 to 18 years of age. N Engl J Med 2004; 351: 1057-1067.

9 Berend N. Contribution of air pollution to COPD and small airway dysfunction. Respirology 2016; 21: 237-244.

10 Gehring U, Gruzieva O, Agius RM, et al. Air pollution exposure and lung function in children: the ESCAPE project. Environ Health Perspect 2013; 121: 1357-1364.

11 Peters JM, Avol E, Gauderman WJ, et al. A study of twelve Southern California communities with differing levels and types of air pollution. II. Effects on pulmonary function. Am J Respir Crit Care Med 1999; 159: 768-775.

12 Gauderman WJ, Urman R, Avol E, et al. Association of improved air quality with lung development in children. N Engl J Med 2015; 372: 905-913.

13 Boogaard H, Fischer PH, Janssen NA, et al. Respiratory effects of a reduction in outdoor air pollution concentrations. Epidemiology 2013; 24: 753-761.

14 Boezen HM, Vonk JM, van der Zee SC, et al. Susceptibility to air pollution in elderly males and females. Eur Respir J 2005; 25: 1018-1024.

15 Johannson KA, Balmes JR, Collard HR. Air pollution exposure: a novel environmental risk factor for interstitial lung disease? Chest 2015; 147: 1161-1167.

\section{Near infrared spectroscopy for the assessment of peripheral tissue oxygenation in pulmonary arterial hypertension}

\section{To the Editor:}

Pulmonary arterial hypertension $(\mathrm{PAH})$ is characterised by increased pulmonary vascular resistance and results in increased morbidity and mortality due to right heart failure and a progressive decline in cardiac output $[1,2]$. The latter disturbs oxygen delivery to the periphery and may lead to pathological changes in tissue oxygenation. The balance between global oxygen supply and demand is reflected in mixed venous oxygen saturation $\left(\mathrm{S}_{\mathrm{VO}_{2}}\right)$, an index that is generally reduced in patients with $\mathrm{PAH}$ [3]. $\mathrm{S}_{\mathrm{VO}}$ at baseline is one of the strongest predictors of survival in $\mathrm{PAH}[4-6]$; this is also true for changes in $\mathrm{SvO}_{2}$ during follow-up [5]. Cut-off values of $60 \%$ [7] and 65\% [5] have been used to distinguish between prognostic groups suggesting that these may be suitable treatment goals. $\mathrm{SvO}_{2}$ is measured invasively in the pulmonary artery, where venous blood mixes after circulating through the superior and inferior vena cava, coronary sinuses and the right-heart chambers.

Spatially resolved near infrared spectroscopy (NIRS) offers a noninvasive, rapidly responsive method for measuring skeletal muscle oxygenation by examining absorption differences in the near-infrared spectrum of 
light between oxy- and deoxy- haemoglobin and myoglobin molecules in the microvasculature. The tissue oxygenation index $\left(\mathrm{StO}_{2}\right)$ is commonly adopted as an index of the dynamic balance between local tissue oxygen supply (availability) and utilisation (extraction) in both health and disease [8,9]. Because the contribution of the myoglobin to the NIRS signal is not critical, $\mathrm{StO}_{2}$ is largely considered as the ratio of oxygenated to total tissue haemoglobin concentration expressed as (oxyhaemoglobin/(oxyhaemoglobin+deoxyhaemoglobin) $\times 100 \%$. To evaluate NIRS in $\mathrm{PAH}$, we correlated measurements of $\mathrm{StO}_{2}$ with $\mathrm{SvO}_{2}$ and venous oxygen saturation in the inferior vena cava $\left(\mathrm{SivcO}_{2}\right)$ during right heart catheterisation.

To measure $\mathrm{StO}_{2}$, one transcutaneous sensor (S-Type Probe, NIRO-200NX spatially resolved spectrophotometer; Hamamatsu Photonics KK, Hamamatsu, Japan) was placed over each vastus lateralis muscle, $10-12 \mathrm{~cm}$ above the lateral epicondyle. $\mathrm{StO}_{2}$ values shown are the average values obtained from both legs at the time of concurrent $\mathrm{SvO}_{2}$ and $\mathrm{SivcO}_{2}$ measurements. $\mathrm{SvO}_{2}$ was measured from the distal port of the Swan-Ganz catheter. $\mathrm{SivcO}_{2}$ was measured with a pigtail catheter advanced through the right internal jugular vein sheath to the level of S1 vertebra.

Concurrent, single-point measurements of $\mathrm{SvO}_{2}$ and $\mathrm{StO}_{2}$ were repeated at supine exercise in consecutive patients who consented to this task. One patient performed straight leg raising and nine patients exercised on an electronically braked lower limb cycle ergometer secured to the catheterisation table. Subjects cycled at 60 revolutions $\mathrm{min}^{-1}$ for $6 \mathrm{~min}$ at a constant workload set at $50 \%$ of peak work rate achieved during an upright cycle cardiopulmonary exercise test the previous day. $\mathrm{SvO}_{2}$ and $\mathrm{StO}_{2}$ were measured during the sixth minute of exercise. Supplementary oxygen was provided as required to minimise arterial hypoxaemia.

25 subjects with PAH (13 idiopathic PAH; one familial PAH; seven connective tissue disease-associated $\mathrm{PAH}$; one congenital heart disease-associated PAH; three portopulmonary arterial hypertension) were studied at rest, 10 of whom also exercised. Resting mean pulmonary artery pressure, cardiac output and pulmonary vascular resistance were $43 \pm 11 \mathrm{mmHg}, 4.6 \pm 1.7 \mathrm{~L} \cdot \mathrm{min}^{-1}$ and $9.5 \pm 5.9 \mathrm{Wood}$ units, respectively.

Combining all the resting and exercise data points $(\mathrm{n}=35), \mathrm{StO}_{2}$ showed a strong correlation with $\mathrm{SvO}_{2}$ $(\mathrm{r}=0.703, \mathrm{p}<0.001)$. This level of correlation persisted when looking separately at rest $\left(\mathrm{StO}_{2}: 73.1 \pm 9.8 \%, \mathrm{SvO}_{2}\right.$ : $62.5 \pm 12.9 \% ; \mathrm{r}=0.701, \mathrm{p}<0.001)$ and exercise data $\left(\mathrm{StO}_{2}: 69.2 \pm 9.2 \%, \mathrm{SvO}_{2}: 42.3 \pm 16.6 \% ; \mathrm{r}=0.863, \mathrm{p}=0.001\right)$ (figure 1) but also, the change in $\mathrm{StO}_{2}$ and $\mathrm{SvO}_{2}$ from rest to exercise $(\mathrm{r}=0.669, \mathrm{p}=0.034)$. A significant reduction was observed in $\mathrm{StO}_{2}$ during exercise (from $77.6 \pm 6.9 \%$ to $69.2 \pm 9.2 \% ; \mathrm{p}<0.001$ ). Resting values of $\mathrm{StO}_{2}$ exhibited similar level of correlation with $\mathrm{SivcO}_{2}(64.2 \pm 14.3 \% ; \mathrm{r}=0.655, \mathrm{p}=0.001)$. A strong correlation $(\mathrm{r}=0.795, \mathrm{p}<0.001)$ was observed between $\mathrm{SivcO}_{2}$ and $\mathrm{SvO}_{2}$, whereas the resting correlations of $\mathrm{StO}_{2}$ with $^{\mathrm{VOO}_{2}}$ and $\mathrm{SivcO}_{2}$ were not statistically different $(\mathrm{Z}=0.3, \mathrm{p}=0.76)$.

Resting $\mathrm{StO}_{2}$ correlated with age $(\mathrm{r}=-0.416, \mathrm{p}=0.038)$ and indices of disease severity including the 6-min walk distance $(\mathrm{r}=0.528, \mathrm{p}=0.008), \mathrm{N}$-terminal pro-brain natriuretic peptide $(\mathrm{r}=-0.395, \mathrm{p}=0.05)$ and diffusing lung capacity for carbon monoxide \% predicted $(\mathrm{r}=0.398, \mathrm{p}=0.049)$.

To our knowledge, this is the first study to report on the association between $\mathrm{StO}_{2}$ and $\mathrm{SvO}_{2}$. Significant correlation between vastus lateralis $\mathrm{StO}_{2}$ and femoral venous oxygen saturation has been reported in healthy trained subjects [10]; although, earlier studies failed to confirm such correlation [11, 12]. However, comparisons should be made with caution as responses of $\mathrm{StO}_{2}$ depend highly on the mode, intensity and duration of exercise and neither of those studies was matched in design to our resting and steady-state
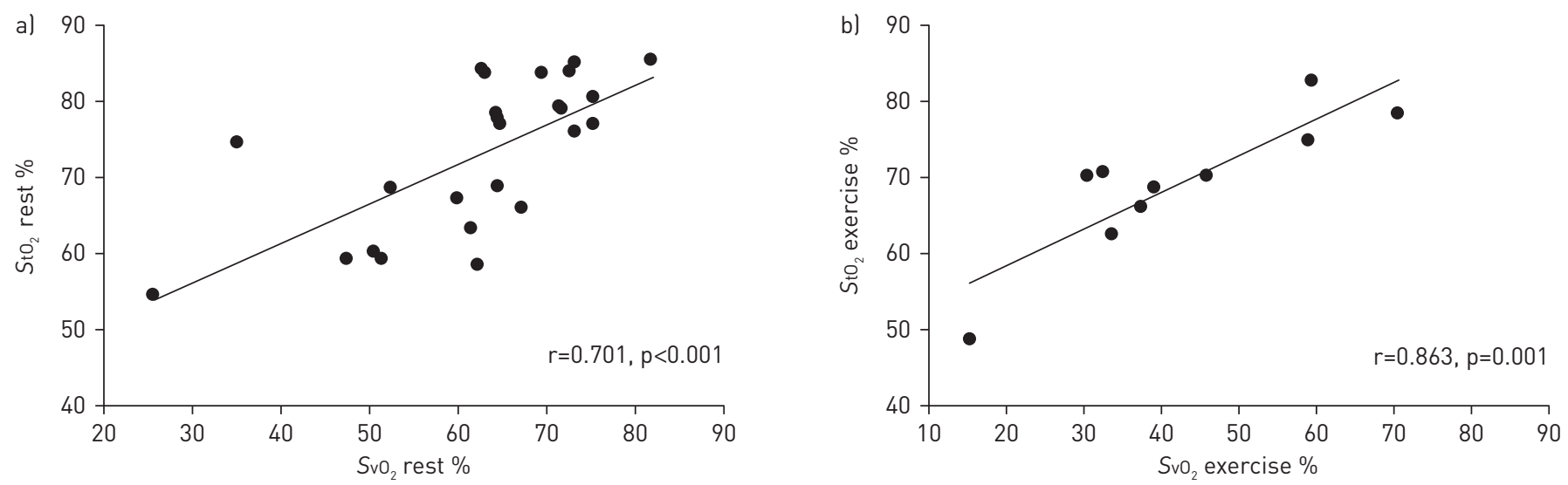

FIGURE 1 Patient characteristics and correlations between tissue oxygenation index $\left(\mathrm{StO}_{2}\right)$ and mixed venous oxygen saturation $\left(\mathrm{SvO}_{2}\right)$ at a) rest and b) exercise. 
exercise protocol. Instead, they reported on measurements either during incremental exercise [10] or over time during constant-load exercise $[11,12]$.

Nonetheless, the correlation between $\mathrm{StO}_{2}$ and $\mathrm{SvO}_{2}$ or $\mathrm{SivcO}_{2}$ is not absolute and results of relating $\mathrm{StO}_{2}$ to venous blood oxygenation should not be interpreted in a quantitative sense. This may be because the specific tissue volume investigated by NIRS is not fully representative of the oxygen status of the body segment (lower limb) or global tissue oxygenation as measured by $\mathrm{SivcO}_{2}$ and $\mathrm{SvO}_{2}$, respectively [8]. It is not surprising that the highest correlations between $\mathrm{StO}_{2}$ and venous oxygen saturation were shown when the sampled venous effluent was specific for the interrogated tissue volume such as that obtained from a deep forearm vein that drained the exercising human muscle ( $r=0.92)$ [9] or from a vein that drained only the electrically simulated canine muscle $(\mathrm{r}=0.97)$ [13]. Accordingly, $\mathrm{StO}_{2}$ would be expected to exhibit a higher correlation with $\mathrm{SivcO}_{2}$ than $\mathrm{SvO}_{2}$; however, we observed similar correlations with $\mathrm{SivcO}_{2}$ and $\mathrm{SvO}_{2}$. This seeming paradox may be due to venous return from the lower limbs being the major determinant of $\mathrm{SvO}_{2}$ in the supine leg exercise.

The design of the present study does not allow for reliable conclusions on the tissue oxygen status per se; the presented findings should be interpreted within the context of oxygen supplementation to maintain resting normoxaemia and the absence of a matched control group. However, our findings provide support for the use of NIRS in the investigation of the pathophysiological abnormalities in PAH. Also, taken together, findings cannot exclude a role of the periphery in the pathophysiology of PAH. Indeed, skeletal muscle tissue microenvironment, an important factor of the local oxygen status, is disturbed in PAH [14]. Perhaps, combination of NIRS with other techniques such as vascular occlusion, sidestream dark field imaging and histological examination could enable further exploration.

Limited experience from application of NIRS in PAH showed significantly lower resting thenar muscle oxygen saturation in $\mathrm{PAH}$ patients compared to matched healthy subjects and patients with chronic heart failure [15]. Also, study of the kinetics of the vastus lateralis fractional oxygen extraction (\% $\Delta$ deoxyhaemoglobin/myoglobin) relative to oxygen uptake at the beginning of heavy-intensity exercise, suggested that patients with PAH have greater microvascular oxygen delivery-to-utilisation inequalities compared to healthy controls, which contributes to a slow adaptation rate of aerobic metabolism [16].

In summary, skeletal muscle $\mathrm{StO}_{2}$ in $\mathrm{PAH}$ subjects correlated significantly with $\mathrm{S}_{\mathrm{vO}_{2}}$ under both resting and exercise conditions. Also, $\mathrm{StO}_{2}$ correlated significantly, albeit weakly, with indices of disease severity. These novel findings suggest that $\mathrm{StO}_{2}$ may serve as a clinical and research tool for the qualitative, noninvasive assessment of the dynamic balance between oxygen supply and utilisation in PAH. Further studies are warranted to explore the value of NIRS in the assessment and prognosis of PAH.

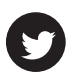

@ERSpublications

Near infrared spectroscopy offers a qualitative, noninvasive indication of mixed venous oxygen saturation in PAH http://ow.ly/TSSx30231YO

Marios Panagiotou ${ }^{1}$, Ioannis Vogiatzis ${ }^{2}$, Zafeiris Louvaris $^{2}$, Geeshath Jayasekera ${ }^{1}$, Alison MacKenzie ${ }^{1}$, Neil Mcglinchey ${ }^{1}$, Julien S. Baker ${ }^{3}$, Alistair C. Church ${ }^{1}$, Andrew J. Peacock ${ }^{1}$ and Martin K. Johnson ${ }^{1}$

${ }^{1}$ Scottish Pulmonary Vascular Unit, Golden Jubilee National Hospital, Glasgow, UK. ${ }^{2}$ National and Kapodistrian University of Athens, Dept of Physical Education and Sports Sciences, Athens, Greece. ${ }^{3}$ Institute of Clinical Exercise and Health Science, University of the West of Scotland, Hamilton, UK.

Correspondence: Marios Panagiotou, Scottish Pulmonary Vascular Unit, Golden Jubilee National Hospital, Agamemnon Street, Glasgow, G81 4DY, UK. E-mail: mariopanag@gmail.com

Received: March 242016 | Accepted after revision: June 132016 | First published online: Sept 012016

Support statement: Marios Panagiotou is the recipient of an ERS PAH Long-Term Research fellowship number LTRF 2014-3106 supported by an unrestricted grant by GSK. Funding information for this article has been deposited with the Open Funder Registry.

Conflict of interest: Disclosures can be found alongside this article at erj.ersjournals.com

\section{References}

1 Galie N, Humbert M, Vachiery JL, et al. 2015 ESC/ERS Guidelines for the diagnosis and treatment of pulmonary hypertension: The Joint Task Force for the Diagnosis and Treatment of Pulmonary Hypertension of the European Society of Cardiology (ESC) and the European Respiratory Society (ERS). Endorsed by: Association for European Paediatric and Congenital Cardiology (AEPC), International Society for Heart and Lung Transplantation (ISHLT). Eur Heart J 2016; 37: 67-119.

2 Galie N, Humbert M, Vachiery JL, et al. 2015 ESC/ERS Guidelines for the diagnosis and treatment of pulmonary hypertension: The Joint Task Force for the Diagnosis and Treatment of Pulmonary Hypertension of the European Society of Cardiology (ESC) and the European Respiratory Society (ERS). Endorsed by: Association for European 
Paediatric and Congenital Cardiology (AEPC), International Society for Heart and Lung Transplantation (ISHLT). Eur Respir J 2015; 46: 903-975.

3 Kielstein JT, Bode-Boger SM, Hesse G, et al. Asymmetrical dimethylarginine in idiopathic pulmonary arterial hypertension. Arterioscler Thromb Vasc Biol 2005; 25: 1414-1418.

4 Sandoval J, Bauerle O, Palomar A, et al. Survival in primary pulmonary hypertension. Validation of a prognostic equation. Circulation 1994; 89: 1733-1744.

5 Nickel N, Golpon H, Greer M, et al. The prognostic impact of follow-up assessments in patients with idiopathic pulmonary arterial hypertension. Eur Respir J 2012; 39: 589-596.

6 Wensel R, Opitz CF, Anker SD, et al. Assessment of survival in patients with primary pulmonary hypertension: importance of cardiopulmonary exercise testing. Circulation 2002; 106: 319-324.

7 Higenbottam T, Butt AY, McMahon A, et al. Long-term intravenous prostaglandin (epoprostenol or iloprost) for treatment of severe pulmonary hypertension. Heart 1998; 80: 151-155.

8 Boushel $\mathrm{R}$, Langberg $\mathrm{H}$, Olesen J, et al. Monitoring tissue oxygen availability with near infrared spectroscopy (NIRS) in health and disease. Scand J Med Sci Sports 2001; 11: 213-222.

9 Mancini DM, Bolinger L, Li H, et al. Validation of near-infrared spectroscopy in humans. J Appl Physiol 1994; 77: 2740-2747.

10 Vogiatzis I, Habazettl H, Louvaris Z, et al. A method for assessing heterogeneity of blood flow and metabolism in exercising normal human muscle by near-infrared spectroscopy. J Appl Physiol 2015; 118: 783-793.

11 Costes F, Barthelemy JC, Feasson L, et al. Comparison of muscle near-infrared spectroscopy and femoral blood gases during steady-state exercise in humans. J Appl Physiol (1985) 1996; 80: 1345-1350.

12 MacDonald MJ, Tarnopolsky MA, Green HJ, et al. Comparison of femoral blood gases and muscle near-infrared spectroscopy at exercise onset in humans. J Appl Physiol (1985) 1999; 86: 687-693.

13 Wilson JR, Mancini DM, McCully K, et al. Noninvasive detection of skeletal muscle underperfusion with near-infrared spectroscopy in patients with heart failure. Circulation 1989; 80: 1668-1674.

14 Panagiotou M, Peacock AJ, Johnson MK. Respiratory and limb muscle dysfunction in pulmonary arterial hypertension: a role for exercise training? Pulm Circ 2015; 5: 424-434.

15 Dimopoulos S, Tzanis G, Manetos C, et al. Peripheral muscle microcirculatory alterations in patients with pulmonary arterial hypertension: a pilot study. Respir Care 2013; 58: 2134-2141.

16 Barbosa PB, Ferreira EM, Arakaki JS, et al. Kinetics of skeletal muscle $\mathrm{O}_{2}$ delivery and utilization at the onset of heavy-intensity exercise in pulmonary arterial hypertension. Eur J Appl Physiol 2011; 111: 1851-1861.

\title{
High burden of prevalent tuberculosis among previously treated people in Southern Africa suggests potential for targeted control interventions
}

\author{
To the Editor:
}

Several studies from Southern Africa report a high risk of tuberculosis (TB) among individuals who have previously been treated for the disease compared to those never before treated [1-5]. In high-burden settings, recurrent $\mathrm{TB}$ may affect large numbers of individuals even after successful treatment, with exogenous reinfection as an important underlying mechanism [2-4]. For example, in Cape Town, South Africa, a city with a high incidence of TB, previously treated individuals constitute one-third of the burden of notified TB [6].

The impact of recurrent disease on TB epidemics in Southern Africa is not well understood. In particular, there is limited knowledge about the extent to which previously treated people contribute to the pool of undiagnosed prevalent TB and transmission in high-burden settings. Two prevalence surveys in Zambia [7] and Zimbabwe [8] reported that previous treatment was strongly associated with prevalent TB among HIV-uninfected individuals. 10 out of 18 smear-positive TB cases detected in a prevalence survey in a South African suburban setting had a history of previous treatment [9], consistent with the hypothesis that previously treated people contribute considerably to TB prevalence and transmission in this setting.

Better quantification of prevalent TB by treatment history can inform estimates of the importance of previously treated individuals for the dynamics of $\mathrm{TB}$ epidemics and help determine if specific interventions targeted to this risk group could accelerate TB control. We therefore aimed to investigate, across 24 African communities, how common a history of previous treatment was, whether the prevalence 